OPEN ACCESS

Edited by: Wolfram Höland, Ivoclar Vivadent, Liechtenstein

Reviewed by: William LaCourse, Alfred University, USA Daqin Chen, Hangzhou Dianzi University, China Christian Rüssel,

Jena University, Germany

${ }^{*}$ Correspondence: Qiang Fu fuq2@corning.com

Specialty section: This article was submitted to Glass Science, a section of the journal Frontiers in Materials

Received: 23 July 2016 Accepted: 17 October 2016 Published: 08 November 2016

Citation:

Fu Q, Wheaton BR, Geisinger KL, Credle AJ and Wang J (2016) Crystallization, Microstructure, and Viscosity Evolutions in Lithium Aluminosilicate Glass-Ceramics.

Front. Mater. 3:49. doi: 10.3389/fmats.2016.00049

\section{Crystallization, Microstructure, and Viscosity Evolutions in Lithium Aluminosilicate Glass-Ceramics}

\author{
Qiang Fu', Bryan R. Wheaton ${ }^{1}$, Karen L. Geisinger ${ }^{1}$, Allen J. Credle ${ }^{1}$ and Jie Wang ${ }^{2}$ \\ ${ }^{1}$ Science and Technology Division, Corning Incorporated, Corning, NY, USA, ${ }^{2}$ Argonne National Laboratory, Center for \\ Nanoscale Materials, Lemont, IL, USA
}

Lithium aluminosilicate glass-ceramics have found widespread commercial success in areas such as consumer products, telescope mirrors, fireplace windows, etc. However, there is still much to learn regarding the fundamental mechanisms of crystallization, especially related to the evolution of viscosity as a function of the crystallization (ceramming) process. In this study, the impact of phase assemblage and microstructure on the viscosity was investigated using high-temperature $X$-ray diffraction (HTXRD), beam bending viscometry (BBV), and transmission electron microscopy (TEM). Results from this study provide a first direct observation of viscosity evolution as a function of ceramming time and temperature. Sharp viscosity increases due to phase separation, nucleation, and phase transformation are noticed through BBV measurement. A nearnet shape ceramming can be achieved in $\mathrm{TiO}_{2}$-containing compositions by keeping the glass at a high viscosity $\left(>10^{9} \mathrm{~Pa}\right.$ s) throughout the whole thermal treatment.

Keywords: lithium aluminosilicate glass-ceramics, crystallization, viscosity, microstructure, phase assemblage

\section{INTRODUCTION}

There have been increasing uses of glass-ceramics in areas such as consumer, biomedical, and construction markets since their discovery by Stookey in 1950s (Stookey, 1960a,b; Holand and Beall, 2002; Zanotto, 2010). Lithium aluminosilicate glass-ceramics have gained considerable commercial success due to the combination of low thermal expansion [coefficient of thermal expansion (CTE), close to $\left.0 \times 10^{-7} /{ }^{\circ} \mathrm{C}\right]$ and high mechanical strength attributed to its two main crystalline phases, $\beta$-quartz and $\beta$-spodumene (keatite) solid solutions (ss) (Ostertag et al., 1968; Holand and Beall, 2002; Dressler et al., 2011a). Both $\mathrm{ZrO}_{2}$ and $\mathrm{TiO}_{2}$ are commonly used as nucleation agents to produce controlled bulk crystallization in the precursor glass (Henderson, 1979; Holand and Beall, 2002; Zanotto, 2010). Although small in concentration, nucleation agents lead to the formation of nuclei for crystal growth (Holand and Beall, 2002). Fine-grained microstructures composed of small crystals $(0.1-1.0 \mu \mathrm{m})$ uniformly distributed in a residual glassy phase are usually observed in lithium aluminosilicate glass-ceramics, which is important to achieve a desired mechanical strength (Beall and Doman, 1987; Beall and Pinckney, 1999; Guedes et al., 2001; Holand and Beall, 2002).

The crystallization process and its associated microstructural evolution are generally studied by differential scanning calorimetry (DSC), X-ray diffraction (XRD), scanning electron microscopy (SEM), or transmission electron microscopy (TEM). Thermal analysis serves as a rapid and convenient technique for the study of the kinetics of chemical reactions and crystallization of glass (Matusita and Sakka, 1980). It has been used to study the crystallization kinetics of various glass systems including the lithium aluminosilicate (Ray and Day, 1990; Barbieri et al., 
1997a; Kim et al., 2004; Fernandes et al., 2008; Wang et al., 2010; Lilensten et al., 2014). Recently, high-temperature X-ray diffraction (HTXRD) and anomalous small-angle X-ray scattering (ASAXS) have been utilized for the in situ observation of the phase transition and structural changes during hightemperature heat treatment (Misture, 2003; Holand et al., 2006; Sinton et al., 2008; Dressler et al., 2011b; Bocker et al., 2013; Lilensten et al., 2014; Raghuwanshi et al., 2014; Kleebusch et al., 2016). Despite the comprehensive understanding of the crystallization mechanism and microstructural changes, the viscosity evolution during the crystallization process remained unclear. However, the control of glass viscosity is critical to achieve a near-net-shape ceramming in the manufacturing of glass-ceramic products (Holand and Beall, 2011).

The objective of this work is to investigate the crystallization, microstructure, and viscosity evolutions in lithium aluminosilicate glass. Both HTXRD and TEM were used to characterize structural evolution in the glass-ceramics during ceramming, while beam bending viscometry (BBV) was used to measure the changes in glass viscosity.

\section{EXPERIMENTAL}

Base glass composition (wt\%) of $67 \mathrm{SiO}_{2}, 25 \mathrm{Al}_{2} \mathrm{O}_{3}, 5.0 \mathrm{Li}_{2} \mathrm{O}$, $1.5 \mathrm{MgO}$, and $1.5 \mathrm{ZnO}$ was prepared by melting a mixture of analytical grade raw materials in platinum crucibles at $1600^{\circ} \mathrm{C}$. $\mathrm{TiO}_{2}(0-10 \mathrm{wt} \%)$ was added on top of the base glass composition to investigate the glass stability with different nucleation agent levels. Table 1 listed the glass compositions for this work. Glasses were poured onto a steel plate to form into patties and then annealed at $600^{\circ} \mathrm{C}$ to remove thermal stress.

Crystalline phases formed in the annealed glasses were detected using XRD. Data were collected from $5^{\circ}$ to $80^{\circ}(2 \theta)$ using a Bruker D4 Endeavor equipped with a LynxEye ${ }^{\mathrm{TM}}$ (Bruker Corporation, Billerica, MA, USA) silicon strip detector. The XRD pattern was analyzed using the PDF-4 database and Jade.

Differential scanning calorimetry was used to determine the non-isothermal kinetic parameters for crystallization. About $40 \mathrm{mg}$ of fine glass powders $(1-10 \mu \mathrm{m})$ was used for the DSC analysis, which was performed with a Netzsch DSC 404 F1 Pegasus. The powders were contained in a platinum cup and heated at $10^{\circ} \mathrm{C} / \mathrm{min}$.

High-temperature XRD was used as an isothermal technique to determine the kinetic parameters for crystallization. In situ HTXRD study was carried out on a PANalytical MPD XRD system equipped with an Anton Paar HTK1200N high-temperature furnace and an X'Celerator multiple strip

TABLE 1 | Glass compositions (wt\%) used for the current study.

\begin{tabular}{lrrrrrrr}
\hline Oxide (wt\%) & $\mathbf{1}$ & \multicolumn{1}{c}{$\mathbf{2}$} & $\mathbf{3}$ & $\mathbf{4}$ & $\mathbf{5}$ & $\mathbf{6}$ & $\mathbf{7}$ \\
\hline $\mathrm{SiO}_{2}$ & 67.0 & 66.6 & 66.3 & 65.3 & 63.8 & 62.3 & 60.9 \\
$\mathrm{Al}_{2} \mathrm{O}_{3}$ & 25.0 & 24.9 & 24.7 & 24.4 & 23.8 & 23.3 & 22.7 \\
$\mathrm{Li}_{2} \mathrm{O}$ & 5.0 & 5.0 & 5.0 & 4.9 & 4.8 & 4.7 & 4.5 \\
$\mathrm{MgO}$ & 1.5 & 1.5 & 1.5 & 1.5 & 1.4 & 1.4 & 1.4 \\
$\mathrm{ZnO}$ & 1.5 & 1.5 & 1.5 & 1.5 & 1.4 & 1.4 & 1.4 \\
$\mathrm{TiO}_{2}$ & 0 & 0.5 & 1.0 & 2.4 & 4.8 & 7.0 & 9.1
\end{tabular}

detector. A polished glass disk $(15 \mathrm{~mm}$ in diameter $\times 1 \mathrm{~mm}$ thick) was used for the analysis. A rapid heating rate, $20^{\circ} \mathrm{C} /$ min, from RT to crystallization temperature was followed by continuous data collection at an isothermal hold temperature. $\mathrm{XRD}$ diffraction traces in the $2 \theta$ range of $10-70^{\circ}$ were collected every $10 \mathrm{~min}$.

The viscosity-temperature behavior of glass was analyzed to investigate the viscosity evolution during ceramming. Glass viscosity below the softening point, in the range of $10^{8}-10^{13}$ $\mathrm{Pa}$ s, was measured using BBV using a three-point bend, BBV1000 beam bending viscometer (Orton Ceramics, Westerville, $\mathrm{OH}$, USA) according to the American Society for Testing and Materials (ASTM) standard (ASTM International, 2013). Briefly, a load was applied on a glass beam $(2.5 \mathrm{~mm} \times 2.5 \mathrm{~mm} \times 55 \mathrm{~mm})$ in a three-point beam bending. To avoid over deformation due
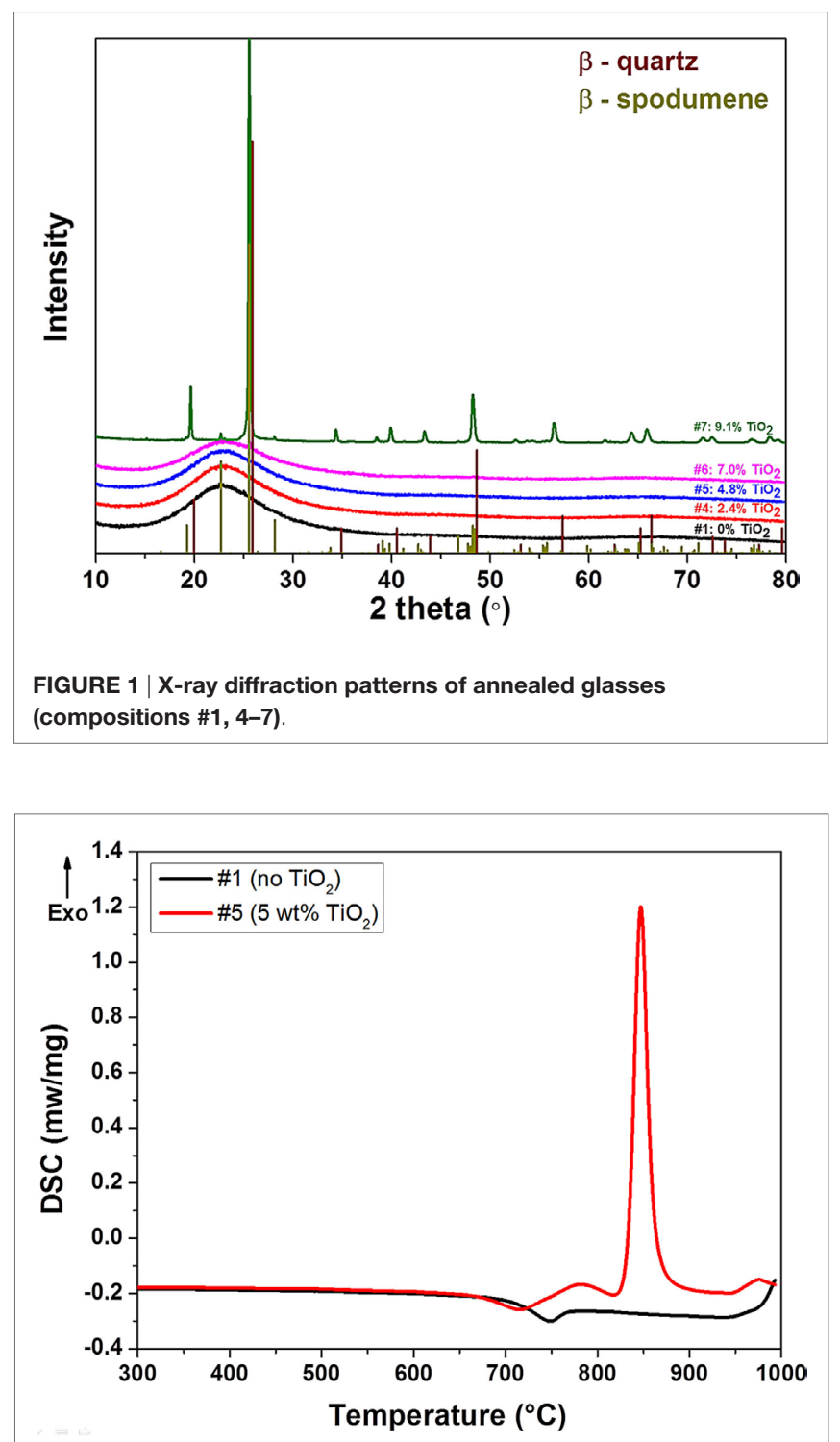

FIGURE 2 | Differential scanning calorimetry of glass compositions $\# 1$ and 5 . 
to low viscosity in the nucleation stage, the measurement of glass viscosity in the crystal growth stage was conducted on beams pre-nucleated at $750^{\circ} \mathrm{C}$ for $2 \mathrm{~h}$.

High-resolution scanning transmission electron microscopy (HRSTEM) was used to observe the detailed crystal morphology and to determine the elemental partitioning in the cerammed samples using energy dispersive X-ray (EDX) elemental mapping. Electron-transparent thin sections of less than $100 \mathrm{~nm}$ were prepared using focused ion beam (FIB) and observed under TEM with $200-\mathrm{kV}$ accelerating voltage.

\section{RESULTS}

\section{Green (Non-Cerammed) Glass}

The addition of $\mathrm{TiO}_{2}$ has a substantial impact on the glass stability. When $\mathrm{TiO}_{2}$ concentrations were below $7.0 \mathrm{wt} \%$, no phase separation or devitrification was observed in glass. However, when more $\mathrm{TiO}_{2}$ (7.0 wt\% or above) was added to the base glass, phase separation (composition \#6) and significant devitrification (composition \#7) were observed in the annealed glasses. XRD analysis in Figure 1 confirmed the amorphous nature of compositions \#1-5. In contrast, a small amount of $\beta$-quartz ss was detected in composition \#6, while a completely devitrified sample was obtained in \#7. Compositions \#1 (no $\mathrm{TiO}_{2}$ ) and \#5 (5.0 wt\% $\mathrm{TiO}_{2}$ ) with no phase separation or devitrification were selected for further studies in this work.

\section{Thermal Analysis}

Figure 2 shows the DSC analysis of the two compositions (\#1 and 5) of interest. The addition of $\mathrm{TiO}_{2}$ to the lithium aluminosilicate glass results in pronounced exothermal reactions in DSC while none in $\mathrm{TiO}_{2}$-free glass. No detectable exothermal peaks were observed in $\mathrm{TiO}_{2}$-free glass (\#1) below $950^{\circ} \mathrm{C}$, while three exothermal peaks were observed in $\mathrm{TiO}_{2}$-containing glass (\#5), indicative of the marked crystallization due to addition of a nucleation agent.
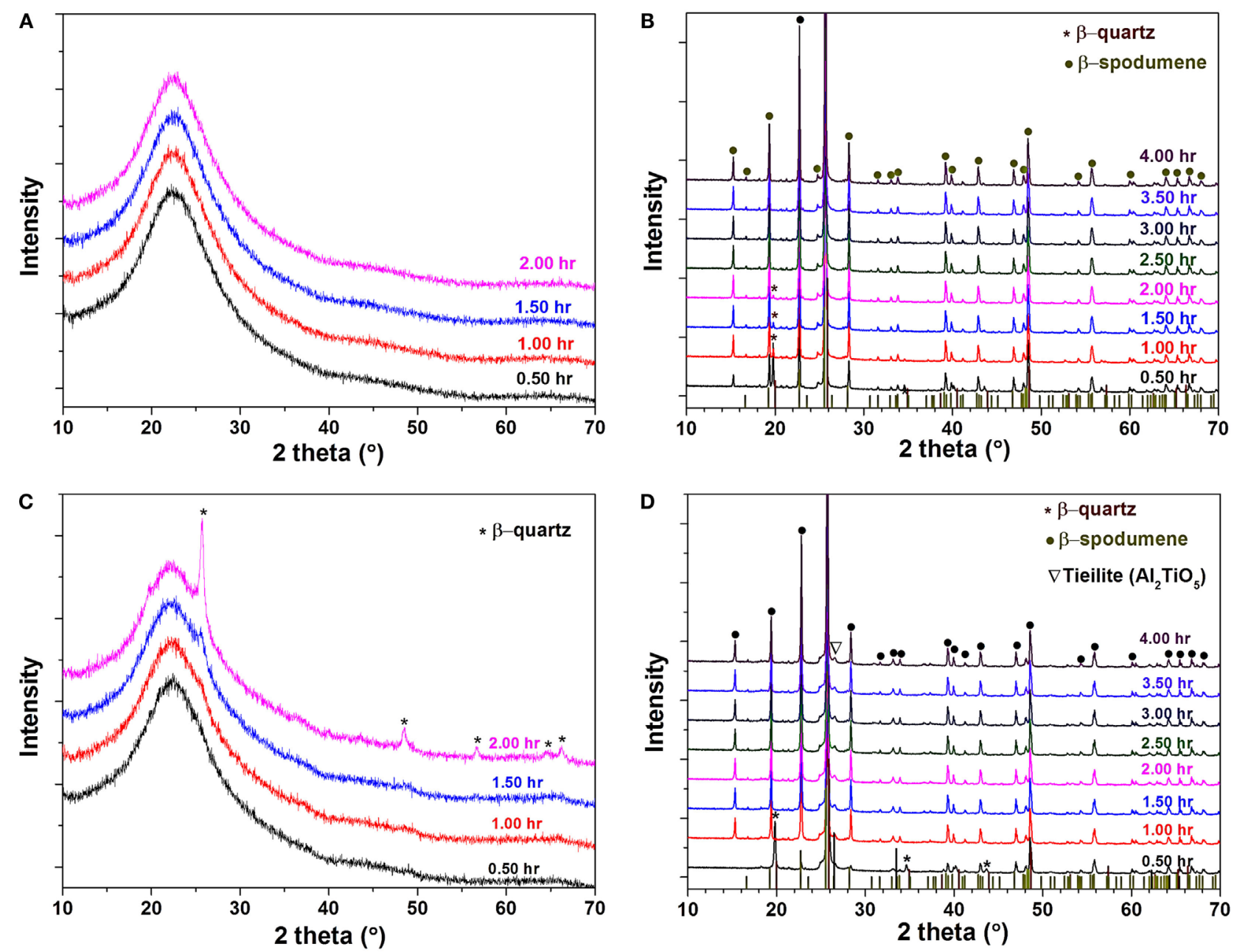

FIGURE 3 | High-temperature X-ray diffraction patterns of glass composition \#1: (A) after nucleation at $750^{\circ} \mathrm{C}$ for $0.5-2.0 \mathrm{~h}$ and (B) after crystal growth at $1050^{\circ} \mathrm{C}$ for $0.5-4.0 \mathrm{~h}$; and of composition \#5: (C) after nucleation at $750^{\circ} \mathrm{C}$ for $0.5-2.0 \mathrm{~h}$ and (D) after crystal growth at $1050^{\circ} \mathrm{C}$ for $0.5-4.0 \mathrm{~h}$. 


\section{Phase Assemblage}

Figure 3 shows the phase assemblage for two glasses at different thermal treatment steps. Based on the DSC analysis, both glasses were first heated at $750^{\circ} \mathrm{C}$ for $2 \mathrm{~h}$ for nucleation and then at $1050^{\circ} \mathrm{C}$ for $4 \mathrm{~h}$ for crystal growth. No crystalline phases were detected in $\mathrm{TiO}_{2}$-free glass (composition \#1) at the nucleation step (Figure 3A), while $\beta$-quartz ss was determined in composition \#5 added with $5 \mathrm{~mol} \% \mathrm{TiO}_{2}$ (Figure 3C), in good agreement with the DSC results. The concentration of $\beta$-quartz ss increased with increasing holding time at $750^{\circ} \mathrm{C}$ for composition $\# 5$ (Figure $3 \mathrm{C}$ ). A fully crystallized body was obtained in both glass compositions after the crystal growth stage $\left(1050^{\circ} \mathrm{C}\right.$ for $\left.4 \mathrm{~h}\right)$. For composition \# 1 , the conversion from $\beta$-quartz ss to $\beta$-spodumene ss did not complete until after $2 \mathrm{~h}$ hold at $1050^{\circ} \mathrm{C}$ (Figure 3B), while in $\mathrm{TiO}_{2}$-containing composition \#5, the conversion completed after $0.5 \mathrm{~h}$ (Figure 3D). The major phase was $\beta$-spodumene ss for the two compositions, while a small amount of tieilite $\left(\mathrm{Al}_{2} \mathrm{O}_{3} \cdot \mathrm{TiO}_{2}\right)$ was detected in composition \#5. It is worth noting that a high number of cracks were formed in composition \#1 due to the lack of volume crystallization, while a crack-free part was achieved in composition $\# 5$.

\section{Microstructure}

Transmission electron microscopy images in Figure 4 show the microstructural changes of composition \#5 during the nucleation hold at $750^{\circ} \mathrm{C}$. For the green glass, no clear feature was observed even at high magnification (Figure 4A). After heat treatment at $750^{\circ} \mathrm{C}$ for $1 \mathrm{~h}$, droplet-like phase was observed in the sample (Figure 4B). The size of the droplets was in the range of 5-10 nm. At a low magnification, $\beta$-quartz ss phase $(50-80 \mathrm{~nm})$ was observed to form in the glass matrix (Figure 4C), which agrees with the XRD results. A higher density of $\beta$-quartz grains was visible after holding at $750^{\circ} \mathrm{C}$ for $4 \mathrm{~h}$ (Figure 4D). The size of the crystal grew slightly falling in the range of 50-100 nm.

A highly crystallized body composed of large grains, and small droplet-like crystals was observed after final heat treatment at $1050^{\circ} \mathrm{C}$ for $4 \mathrm{~h}$ (Figure 5A). Combined with XRD results (Figure 3D), the large grains were determined to be $\beta$-spodumene ss and small droplets tieilite. The size of $\beta$-spodumene grains was in the range of $0.3-1.0 \mu \mathrm{m}$ while tieilite $30-50 \mathrm{~nm}$ (Figure 5B). Elemental mapping confirmed that the droplets were rich in $\mathrm{Al}$ and Ti (Figures 5C,D).

\section{Viscosity Evolution}

Figure 6 shows the viscosity evolution for the two selected glasses as a function of ceramming cycle. For composition \#1 without nucleation agent, the viscosity decreased monotonically with increasing temperatures, consistent with most glass compositions. The measurement was stopped at $875^{\circ} \mathrm{C}$ due to its
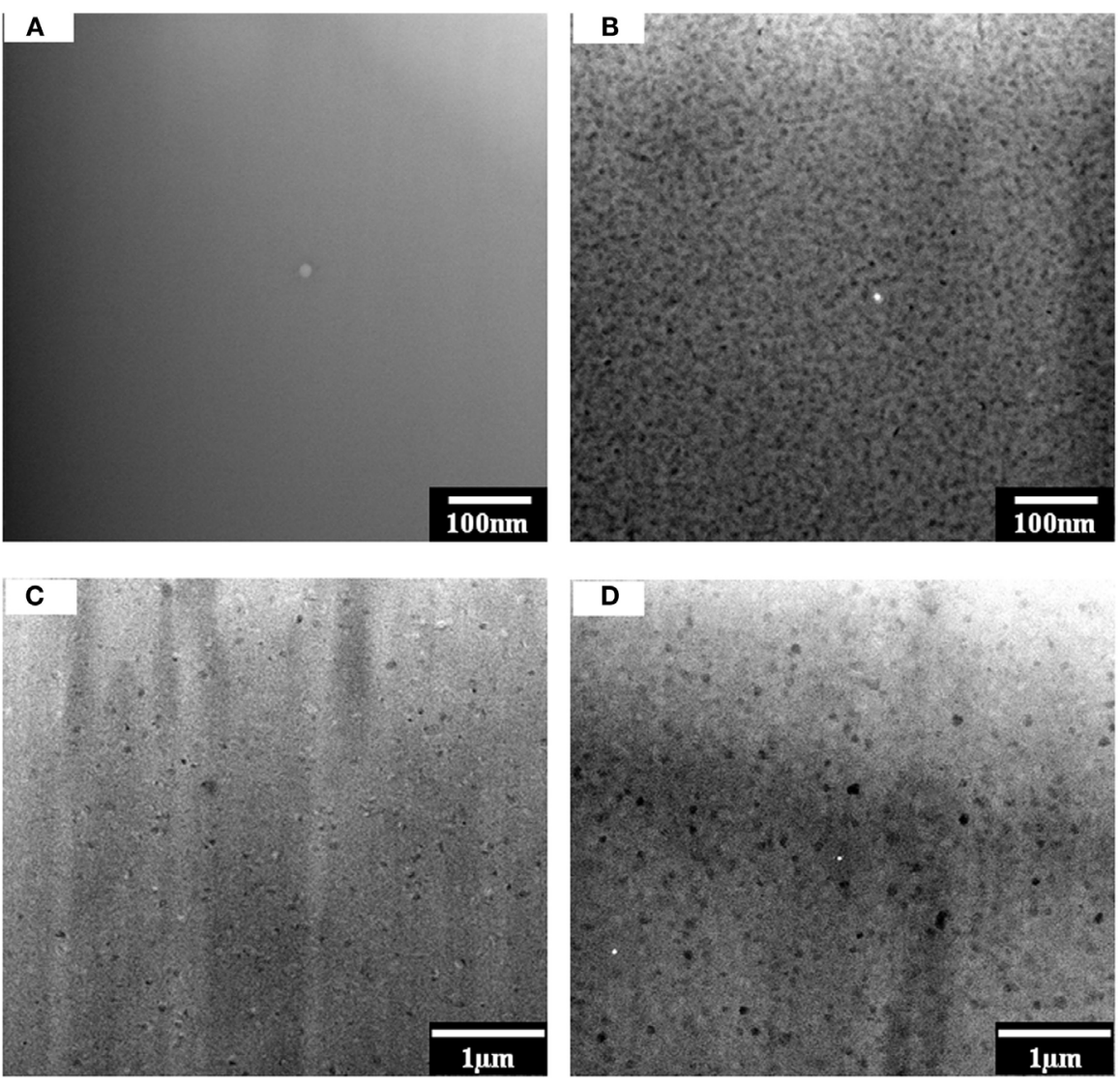

FIGURE 4 | TEM of nucleated glass composition \#5: (A) green glass; (B) after holding at $750^{\circ} \mathrm{C}$ for $1.0 \mathrm{~h}$ showing phase separation; (C) low magnification showing the formation of $\beta$-quartz ss after at $750^{\circ} \mathrm{C}$ for $1.0 \mathrm{~h}$; (D) more $\beta$-quartz ss after holding at $750^{\circ} \mathrm{C}$ for $4.0 \mathrm{~h}$. 

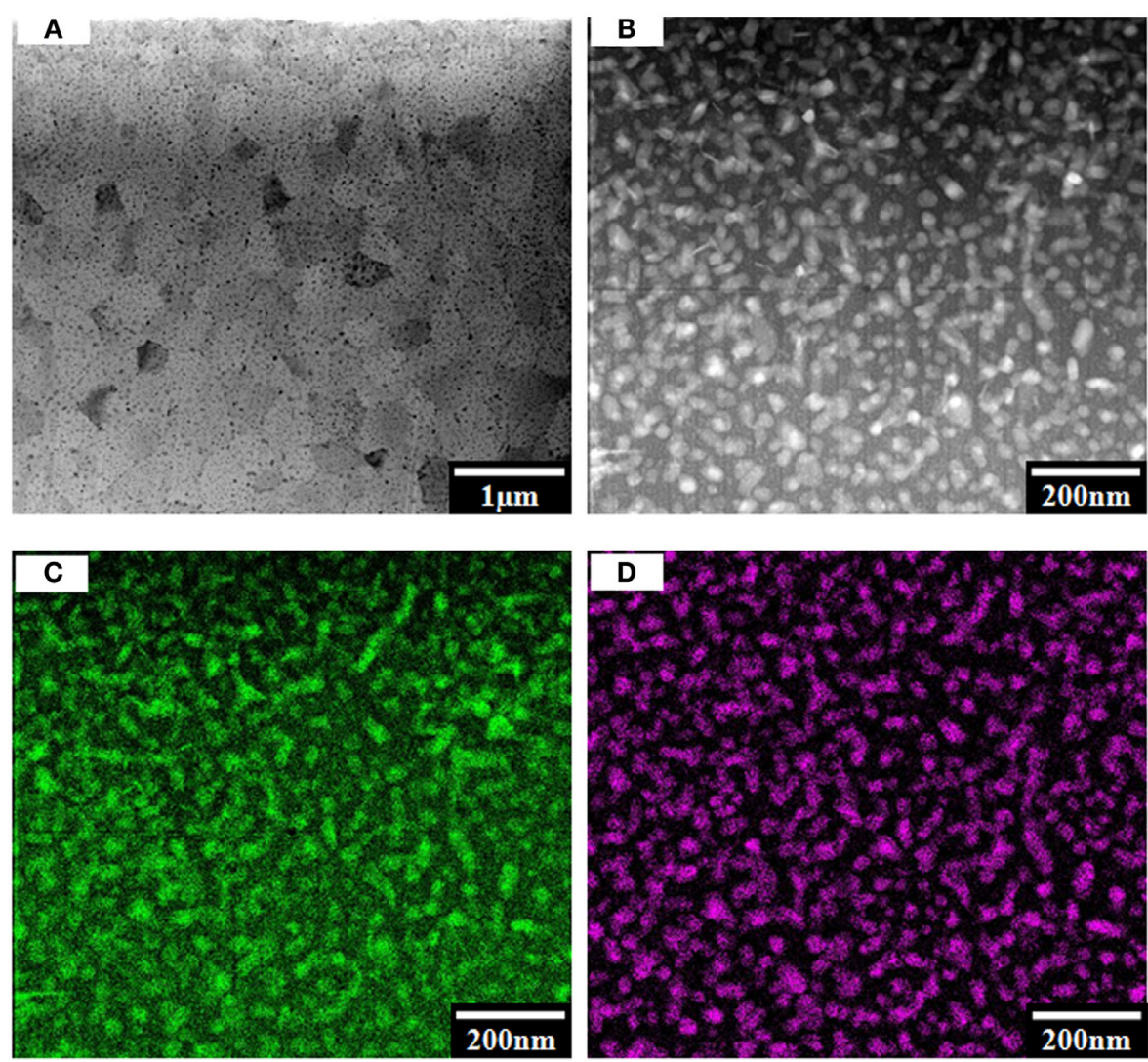

FIGURE 5 | TEM images showing microstructure and elemental mapping of composition \#5 after holding at $1050^{\circ} \mathrm{C}$ for $4.0 \mathrm{~h}$ : (A) overview of microstructure; (B) high-magnification image showing the fine crystals; (C) Al map of (B); (D) Ti map of (B)

low viscosity, close to $10^{8} \mathrm{~Pa}$ s, which was below the measurement limit for the BBV method. The viscosity remained almost unchanged during the holding at $750^{\circ} \mathrm{C}$, corresponding well with the HTXRD study which shows little to no structural change in this glass (Figure $\mathbf{3 A}$ ). At the end of ceramming cycle, the glass cracked into pieces due to the lack of effective bulk nucleation.

In contrast, the change of viscosity for the $\mathrm{TiO}_{2}$-containing glass (composition \#5) as a function of ceramming temperature was much more complicated than the monotonic decrease of viscosity in $\mathrm{TiO}_{2}$-free glass (Figure 6B). The viscosity plot could be divided into three stages. At stage I, an increase of one order of magnitude in viscosity was observed during the hold at $750^{\circ} \mathrm{C}$, suggesting either phase separation or nucleation at this stage. At stage II, an abrupt decrease of viscosity with increasing temperature was observed after the initial nucleation hold until $824^{\circ} \mathrm{C}$, at which temperature a sharp increase in viscosity was noticed. The temperature for the jump in viscosity was exactly the onset temperature for the largest exothermal peak in DSC (Figure 2), which was confirmed by XRD to be the formation of $\beta$-quartz (Figure 3C). At this stage, the major phase in composition \#5 was $\beta$-quartz ss with very little amount of glassy phase, suggesting a high viscosity during ceramming. Once the reaction completed, the viscosity of composition \#5 started to decrease with increasing temperature due to the lack of new crystalline phase formation and the relatively stable structure. At stage III, $\beta$-quartz ss was converted to $\beta$-spodumene ss and no further structural change during the holding at $1050^{\circ} \mathrm{C}$, as evidenced by the small variation in viscosity and the unchanged phase assemblage in HTXRD (Figure 3D). Overall, the viscosity of the $\mathrm{TiO}_{2}$-containing glass was kept above $10^{9.5} \mathrm{~Pa}$ s during the whole ceramming cycle, which contributed to a near-netshape ceramming of composition \#5 without cracking or visible deformation.

\section{DISCUSSION}

Numerous investigations have been conducted to understand the crystallization process in $\mathrm{Li}_{2} \mathrm{O}-\mathrm{Al}_{2} \mathrm{O}_{3}-\mathrm{SiO}_{2}$ glass-ceramic family due to their increased commercial applications. Nucleation agents, either single or a combination of several, including $\mathrm{TiO}_{2}$, $\mathrm{ZrO}_{2}, \mathrm{P}_{2} \mathrm{O}_{5}$, and $\mathrm{Ta}_{2} \mathrm{O}_{5}$ have been used to produce a bulk nucleation owing to a liquid-liquid phase separation (Barbieri et al., 1997b; Guedes et al., 2001; Wurth et al., 2009; Ananthanarayanan et al., 2010; Li et al., 2010; Nemati et al., 2010; Höche et al., 2011; Höche et al., 2012; Montedo et al., 2012; Chavoutier et al., 2014; Kleebusch et al., 2016; Soares and Zanotto, 2016). Although minor in concentration, nucleation agents are critical to the final microstructure and properties of glass-ceramics. This work 

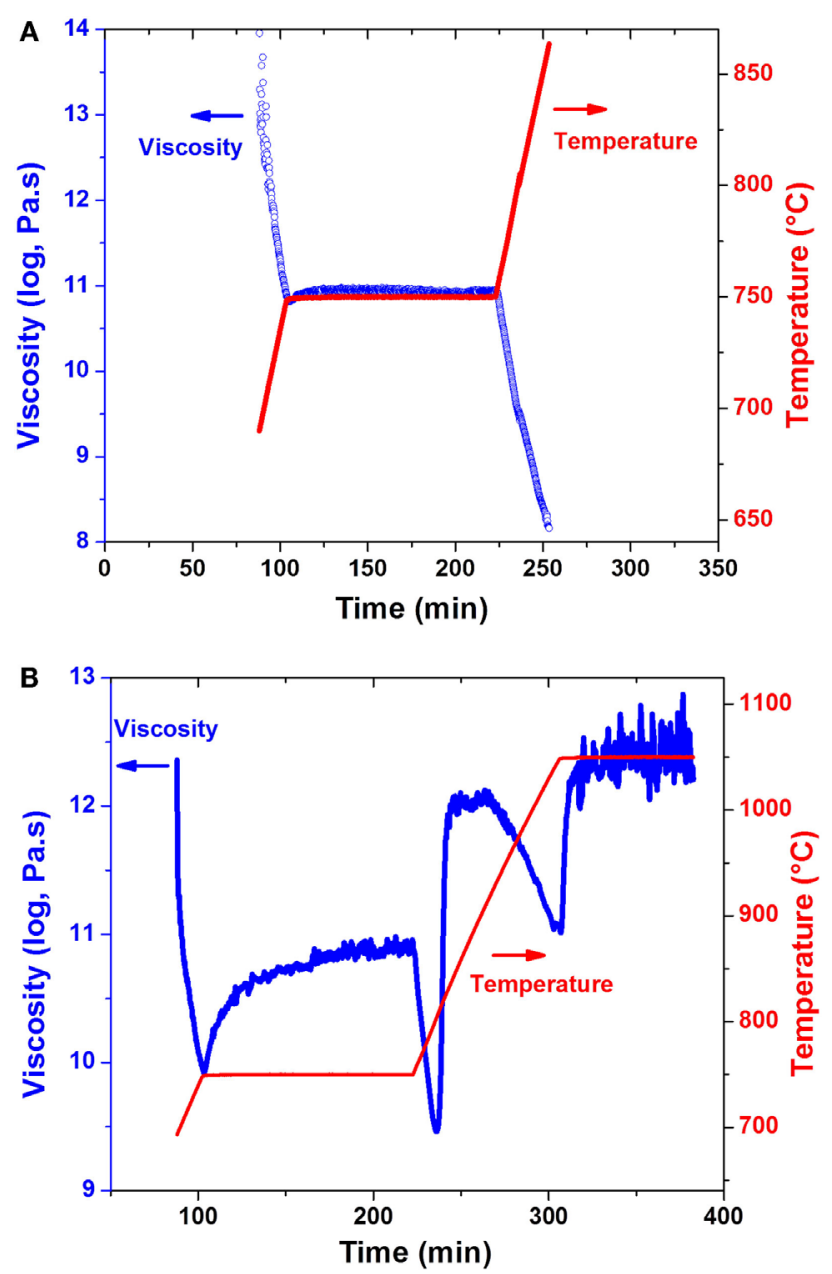

FIGURE 6 | Viscosity-time-temperature plots of glass compositions (A) \#1 and (B) \#5 as a function of heat treatment.

studies the crystallization, and microstructural and viscosity evolutions in $\mathrm{Li}_{2} \mathrm{O}-\mathrm{Al}_{2} \mathrm{O}_{3}-\mathrm{SiO}_{2}$ glass. It is found that $\mathrm{TiO}_{2}$ impacts the properties of both green glass and glass-ceramic. In green glass, a higher concentration of $\mathrm{TiO}_{2}$ results in a high tendency for devitrification and a less thermal stability (Figures 1 and 2). Therefore, the level of $\mathrm{TiO}_{2}$ must be controlled within a proper range to obtain a stable glass without devitrification for a glassceramic composition.

Both the phase assemblage and microstructure of lithium aluminosilicate glass-ceramics are influenced by the presence of $\mathrm{TiO}_{2}$. When a proper amount of $\mathrm{TiO}_{2}$ was added to the $\mathrm{Li}_{2} \mathrm{O}-$ $\mathrm{Al}_{2} \mathrm{O}_{3}-\mathrm{SiO}_{2}$ glass, phase separation was developed at the nucleation stage, which led to the formation of $\beta$-quartz ss (Figures 3 and 4). This is consistent with previous reports that the addition of $\mathrm{TiO}_{2}$ produced $\mathrm{TiO}_{2}$-rich phase and serves as a nucleation phase for the formation of $\beta$-quartz ss (Doherty et al., 1967; Barbieri et al., 1997b,c; Nordmann and Cheng, 1997; Bhattacharyya et al., 2009). In contract, the $\mathrm{TiO}_{2}$-free glass remained amorphous at this nucleation stage (Figure 3 ).
The viscosity of the system exhibits a strong dependence on the phase assemblage and structure of each composition. The monotonic decrease of viscosity as a function of ceramming cycle for $\mathrm{TiO}_{2}$-free composition \#1 agrees well with the HTXRD and DSC analysis, both of which show no evidence of new phase formation within the tested temperature range. In contract, three distinct stages were observed in the viscosity of $\mathrm{TiO}_{2}$-containing composition \#5 (Figure 6), corresponding well with the thermal events determined by DSC (Figure 2), phase assemblage evolution by HTXRD (Figure 3), and microstructural change by TEM (Figures 4 and 5). At stage $I$, the increasing viscosity at the nucleation hold was mainly attributed to $\beta$-quartz ss formation; at stage II, the abrupt increase in viscosity was a direct consequence of the formation of high concentration of $\beta$-quartz ss phase; and at stage III, the conversion $\beta$-quartz to $\beta$-spodumene ss was completed, which produced a fully crystallized glass-ceramic with little glassy phase and a high-viscosity cerammed body. The increase of viscosity due to crystallization was also observed in a lithium aluminosilicate glass containing $\mathrm{ZrO}_{2}$ and $\mathrm{TiO}_{2}$ as nucleation agents. A higher $T_{\mathrm{g}}$ was reported in the nucleated glass than in the precursor glass due to the presence of $\beta$-quartz phase (Wurth et al., 2009). The formation of an alumina-rich layer surrounding a $\mathrm{ZrTiO}_{4}$-rich core was reported to account for the increase of viscosity (Raghuwanshi et al., 2014). However, no direct analysis of the viscosity evolution in this system has been conducted. The increase in glass viscosity due to the nucleation in $\mathrm{TiO}_{2}$-containing lithium aluminosilicate glass has been investigated in a previous study using a fiber elongation method, although the measurement was done on a post-treated sample not an in situ measurement during ceramming (Kim et al., 2004). The viscosity of the nucleated composite was decided by the concentration of the crystalline phase and the residual glass composition. The relationship between viscosity and the presence of the crystalline phase was described using the following equation (Kim et al., 2004):

$$
\frac{\eta_{\text {app }}}{\eta_{g}}=(1-\alpha)^{-3}
$$

where $\eta_{\text {app }}$ is the apparent viscosity of the crystallized glass, $\eta_{\mathrm{g}}$ the viscosity of the precursor glass, and $\alpha$ the volume fraction of crystalline phase. Based on Eq. 1, a higher concentration of $\beta$-quartz ss phase led to a high viscosity in the crystallized glass, which was in agreement with the TEM observation and viscosity measurement (Figures 4 and 6). Additionally, with the formation of $\beta$-quartz ss $\left(\mathrm{Li}_{2} \mathrm{O} \cdot \mathrm{Al}_{2} \mathrm{O}_{3} \cdot 4 \mathrm{SiO}_{2}\right)$, a highly siliceous residual glass was developed, which increased the viscosity of the system. The finding in our in situ viscosity measurement at the nucleation step was consistent with the previous reports. Our in situ measurement throughout the full ceramming cycle established the viscosity-temperature-time relationship for the first time.

\section{CONCLUSION}

An investigation on the evolutions of crystallization, microstructure, and viscosity in lithium aluminosilicate glass was conducted in this work. The addition of a nucleation agent 
$\left(\mathrm{TiO}_{2}\right)$ was found to have a marked impact on the properties in both the glass and glass-ceramics. At the nucleation stage, phase separation and formation of $\beta$-quartz ss phase were observed, resulting in an increase of one order of magnitude in viscosity in $\mathrm{TiO}_{2}$-containing glass. In contrast, the viscosity in $\mathrm{TiO}_{2}$-free glass showed a monotonic decrease in viscosity when cerammed using the same cycle. Further viscosity variation due to crystallization and crystal growth was also observed in $\mathrm{TiO}_{2}$-containing glass. The glass viscosity demonstrated a strong dependence on the phase assemblage and structural changes during ceramming

\section{REFERENCES}

Ananthanarayanan, A., Kothiyal, G. P., Montagne, L., and Revel, B. (2010). MAS-NMR studies of lithium aluminum silicate (LAS) glasses and glass-ceramics having different $\mathrm{Li}_{2} \mathrm{O} / \mathrm{Al}_{2} \mathrm{O}_{3}$ ratio. J. Solid State Chem. 183, 120-127. doi:10.1016/j.jssc.2009.10.006

ASTM International. (2013). "Standard test method for annealing point and strain point of glass by beam bending," in ASTM C598-93 (West Conshohocken, PA).

Barbieri, L., Leonelli, C., Manfredini, T., Siligardi, C., and Corradi, A. B. (1997a). Nucleation and crystallization of a lithium aluminosilicate glass. J. Am. Ceram. Soc. 80, 3077-3083. doi:10.1111/j.1151-2916.1997.tb03235.x

Barbieri, L., Corradi, A. B., Leonelli, C., Siligardi, C., Manfredini, T., and Pellacani, G. C. (1997b). Effect of $\mathrm{TiO}_{2}$ addition on the properties of complex aluminosilicate glasses and glass-ceramics. Mater. Res. Bull. 32, 637-648. doi:10.1016/ S0025-5408(97)00029-9

Barbieri, L., Leonelli, C., Manfredini, T., Siligardi, C., Corradi, A. B., Mustarelli, P., et al. (1997c). Nucleation and crystallization of a lithium aluminosilicate glass. J. Am. Ceram. Soc. 80, 3077-3083. doi:10.1111/j.1151-2916.1997. tb03235.x

Beall, G. H., and Doman, R. C. (1987). "Glass-ceramics," in Encyclopedia of Physical Science and Technology, ed. R. A. Meyer. (New York: Academic Press), Vol. 6, 294-307.

Beall, G. H., and Pinckney, L. R. (1999). Nanophase glass-ceramics. J. Am. Ceram. Soc. 82, 5-16. doi:10.1111/j.1151-2916.1999.tb01716.x

Bhattacharyya, S., Höche, T., Jinschek, J. R., Avramov, I., Wurth, R., Mu“ller, M., et al. (2009). Direct evidence of Al-rich layers around nanosized $\mathrm{ZrTiO}_{4}$ in glass: putting the role of nucleation agents in perspective. Cryst. Growth Des. 10, 379-385. doi:10.1021/cg9009898

Bocker, C., Rüssel, C., and Avramov, I. (2013). Transparent nano crystalline glass-ceramics by interface controlled crystallization. Int. J. Appl. Glass Sci. 4, 174-181. doi:10.1111/ijag.12033

Chavoutier, M., Caurant, D., Majérus, O., Boulesteix, R., Loiseau, P., Jousseaume, C., et al. (2014). Effect of $\mathrm{TiO}_{2}$ content on the crystallization and the color of $\left(\mathrm{ZrO}_{2}, \mathrm{TiO}_{2}\right)$-doped $\mathrm{Li}_{2} \mathrm{O}-\mathrm{Al}_{2} \mathrm{O}_{3}-\mathrm{SiO}_{2}$ glasses. J. Non-Cryst. Solids 384, 15-24. doi:10.1016/j.jnoncrysol.2013.03.034

Doherty, P., Lee, D., and Davis, R. (1967). Direct observation of the crystallization of $\mathrm{Li}_{2} \mathrm{O}-\mathrm{Al}_{2} \mathrm{O}_{3}-\mathrm{SiO}_{2}$ glasses containing $\mathrm{TiO}_{2}$. J. Am. Ceram. Soc. 50, 77-81. doi: 10.1111/j.1151-2916.1967.tb15043.x

Dressler, M., Rüdinger, B., and Deubener, J. (2011a). An in situ high-temperature X-ray diffraction study of early-stage crystallization in lithium aluminosilicate glass-ceramics. J. Am. Ceram. Soc. 94, 1421-1426. doi:10.1111/j.1551-2916.2010.04252.x

Dressler, M., Rüdinger, B., and Deubener, J. (2011b). An in situ high-temperature X-ray diffraction study of early-stage crystallization in lithium alumosilicate glass-ceramics. J. Am. Ceram. Soc. 94, 1421-1426. doi:10.1111/j.1551-2916.2010.04252.x

Fernandes, H. R., Tulyaganov, D. U., Goel, I. K., and Ferreira, J. M. F. (2008). Crystallization process and some properties of $\mathrm{Li}_{2} \mathrm{O}-\mathrm{SiO}_{2}$ glass-ceramics doped with $\mathrm{Al}_{2} \mathrm{O}_{3}$ and $\mathrm{K}_{2} \mathrm{O}$. J. Am. Ceram. Soc. 91, 3698-3703. doi:10.1111/j.1551-2916.2008.02724.x

Guedes, M., Ferro, A. C., and Ferreira, J. M. F. (2001). Nucleation and crystal growth in commercial LAS compositions. J. Eur. Ceram. Soc. 21, 1187-1194. doi:10.1016/S0955-2219(00)00333-2 as supported by HTXRD, DSC, and TEM analysis. Last but not the least, the addition of $\mathrm{TiO}_{2}$ helped achieve a near-net shape ceramming due to the high glass viscosity throughout the whole thermal treatment, which was critical for the manufacturing of products with complicated three-dimensional shapes.

\section{AUTHOR CONTRIBUTIONS}

All authors conducted experiments and contributed to the writing of the draft.

Henderson, D. (1979). Experimental analysis of non-isothermal transformations involving nucleation and growth. J. Therm. Anal. 15, 325-331. doi:10.1007/ BF01903656

Höche, T., Mäder, M., Bhattacharyya, S., Henderson, G. S., Gemming, T., Wurth, R., et al. (2011). $\mathrm{ZrTiO}_{4}$ crystallisation in nanosized liquid-liquid phase-separation droplets in glass - a quantitative XANES study. CrystEngComm 13, 2550-2556. doi:10.1039/c0ce00716a

Holand, W., Apel, E., van 't Hoen, C., and Rheinberger, V. (2006). Studies of crystal phase formations in high-strength lithium disilicate glass-ceramics. J. NonCryst. Solids 352, 4041-4050. doi:10.1016/j.jnoncrysol.2006.06.039

Holand, W., and Beall, G. (2002). Glass-Ceramic Technology. Hoboken, NJ: John Wiley \& Sons, Inc.

Holand, W., and Beall, G. (2011). Glass-Ceramic Technology, 2nd Edn. Hoboken, NJ: John Wiley \& Sons, Inc.

Höche, T., Patzig, C., Gemming, T., Wurth, R., Rüssel, C., and Avramov, I. (2012). Temporal evolution of diffusion barriers surrounding $\mathrm{ZrTiO}_{4}$ nuclei in lithia aluminosilicate glass-ceramics. Cryst. Growth Des. 12, 1556-1563. doi:10.1021/ $\operatorname{cg} 2016148$

Kim, K. D., Lee, S. H., and Ahn, H. K. (2004). Observation of nucleation effect on crystallization in lithium aluminosilicate glass by viscosity measurement. J. Non-Cryst. Solids 336, 195-201. doi:10.1016/j.jnoncrysol.2004. 01.001

Kleebusch, E., Patzig, C., Höche, T., and Rüssel, C. (2016). Effect of the concentrations of nucleating agents $\mathrm{ZrO}_{2}$ and $\mathrm{TiO}_{2}$ on the crystallization of $\mathrm{Li}_{2} \mathrm{O}$ $\mathrm{Al}_{2} \mathrm{O}_{3}-\mathrm{SiO}_{2}$ glass: an X-ray diffraction and TEM investigation. J. Sci. Mater. 51, 10127-10138. doi:10.1007/s10853-016-0241-9

Li, Y., Liang, K., Xu, B., and Cao, J. (2010). Crystallization mechanism and microstructure evolution of $\mathrm{Li}_{2} \mathrm{O}-\mathrm{Al}_{2} \mathrm{O}_{3}-\mathrm{SiO}_{2}$ glass-ceramics with $\mathrm{Ta}_{2} \mathrm{O}_{5}$ as nucleating agent. J. Therm. Anal. Calorim. 101, 941-948. doi:10.1007/s10973009-0598-y

Lilensten, L., Fu, Q., Wheaton, B. R., Credle, A. J., Stewart, R. L., and Kohli, J. T. (2014). Kinetic study on lithium-aluminosilicate (LAS) glass-ceramics containing $\mathrm{MgO}$ and $\mathrm{ZnO}$. Ceram. Int. 40, 11657-11661. doi:10.1016/j. ceramint.2014.03.171

Matusita, K., and Sakka, S. (1980). Kinetic study on crystallization of glass by differential thermal analysis-criterion on application of Kissinger plot. J. NonCryst. Solids 38-39, 741-746. doi:10.1016/0022-3093(80)90525-6

Misture, S. T. (2003). Large-volume atmosphere-controlled high-temperature X-ray diffraction furnace. Meas. Sci. Technol. 14, 1091. doi:10.1088/0957 $0233 / 14 / 7 / 326$

Montedo, O. R. K., Hotza, D., de Oliveira, A. P. N., Meszaros, R., Travitzky, N., and Greil, P. (2012). Crystallisation kinetics of $\beta$-spodumene-based glass ceramic. Adv. Mater. Sci. Eng. 2012, 8. doi:10.1155/2012/525428

Nemati, A., Goharian, P., Shabanian, M., and Afshar, A. (2010). Effects of nucleation agent particle size on properties, crystallisation and microstructure of glass-ceramics in $\mathrm{TiO}_{2}-\mathrm{ZrO}_{2}-\mathrm{Li}_{2} \mathrm{O}-\mathrm{CaO}-\mathrm{Al}_{2} \mathrm{O}_{3}-\mathrm{SiO}_{2}$ system. Adv. Appl. Ceram. 109, 318-323. doi:10.1179/174367609X422063

Nordmann, A., and Cheng, Y.-B. (1997). Crystallization behaviour and microstructural evolution of a $\mathrm{Li}_{2} \mathrm{O}-\mathrm{Al}_{2} \mathrm{O}_{3}-\mathrm{SiO}_{2}$ glass derived from spodumene mineral. J. Sci. Mater. 32, 83-89. doi:10.1023/A:1018519030791

Ostertag, W., Fischer, G. R., and Williams, J. P. (1968). Thermal expansion of synthetic $\beta$-spodumene and $\beta$-spodumene-silica solid solutions. J. Am. Ceram. Soc. 51, 651-654. doi:10.1111/j.1151-2916.1968.tb12638.x 
Raghuwanshi, V. S., Rüssel, C., and Hoell, A. (2014). Crystallization of $\mathrm{ZrTiO}_{4}$ nanocrystals in lithium-alumino-silicate glass ceramics: anomalous small-angle X-ray scattering investigation. Cryst. Growth Des. 14, 2838-2845. doi:10.1021/ cg5001232

Ray, C. S., and Day, D. E. (1990). Determining the nucleation rate curve for lithium disilicate glass by differential thermal-analysis. J. Am. Ceram. Soc. 73, 439-442. doi:10.1111/j.1151-2916.1990.tb06532.x

Stookey, S. D. (1960a). Method of Making Ceramics and Product Thereof. US Patent Vol. 2920971. Corning Glass Works, USA.

Stookey, S. D. (1960b). Method of Making a Semicrystalline Ceramic Body. US Patent Vol. 2933857.

Sinton, C. W., Crawford, A., Misture, S., Seeger, J., Wondraczek, L., and Deubener, J. (2008). High temperature reactions between soda-lime-silica glass and lithium aluminosilicate glass-ceramics. Glass Technol. Eur. J. Glass Sci. Technol. A 49, 133-138.

Soares, V. O., and Zanotto, E. D. (2016). Effect of $\mathrm{P}_{2} \mathrm{O}_{5}$ on the nonisothermal sinter-crystallization process of a lithium aluminum silicate glass. Int. J. Appl. Ceram. Technol. 13, 948-955. doi:10.1111/ijac.12540

Wang, M.-C., Li, W.-L., Cheng, C.-W., Chang, K.-M., Chen, Y.-F., and Hsi, C.-S. (2010). The phase transformation and crystallization kinetics of (1-x) $\mathrm{Li}_{2} \mathrm{O}-\mathrm{xNa}_{2} \mathrm{O}-\mathrm{Al}_{2} \mathrm{O}_{3}-4 \mathrm{SiO}_{2}$ glasses. Materials Chemistry and Physics 123, 203-209. doi:10.1016/j.matchemphys.2010.03.083

Wurth, R., Munoz, F., Müller, M., and Rüssel, C. (2009). Crystal growth in a multicomponent lithia aluminosilicate glass. Mater. Chem. Phys. 116, 433-437. doi:10.1016/j.matchemphys.2009.04.010

Zanotto, E. D. (2010). A bright future for glass-ceramics. Am. Ceram. Soc. Bull. $89,19-27$.

Conflict of Interest Statement: The authors declare that the research was conducted in the absence of any commercial or financial relationships that could be construed as a potential conflict of interest.

Copyright (C) $2016 \mathrm{Fu}$, Wheaton, Geisinger, Credle and Wang. This is an open-access article distributed under the terms of the Creative Commons Attribution License (CC BY). The use, distribution or reproduction in other forums is permitted, provided the original author(s) or licensor are credited and that the original publication in this journal is cited, in accordance with accepted academic practice. No use, distribution or reproduction is permitted which does not comply with these terms. 